\title{
Cardiovascular and safety events of PCSK9 inhibitors in statin-treated patients with cardiovascular risk: A Systematic Review and Meta- Analysis
}

\author{
Zinan Zhao ${ }^{1}$, Xin $\mathrm{Hu}^{1}$, Yatong Zhang ${ }^{1}$, Deping $\mathrm{Liu}^{2 *}$
}

${ }^{1}$ Department of Pharmacy, Beijing Hospital, National Center of Gerontology; Institute of Geriatric Medicine, Chinese Academy of Medical Sciences, P.R. China; ${ }^{2}$ Department of Cardiology, Beijing Hospital, National Center of Gerontology; Institute of Geriatric Medicine, Chinese Academy of Medical Sciences, P.R. China

Received, October 10, 2020; Revised, October 26, 2020; Accepted, October 30, 2020; Published, November 1, 2020

Corresponding author: Deping Liu, Department of Cardiology, Beijing Hospital, National Center of Gerontology; Institute of Geriatric Medicine, Chinese Academy of Medical Sciences, P.R. China. POSTAL ADDRESS: No. 1 Dahua Road, Dongdan, Dongcheng District, Beijing, China; email: 1liudeping@263.net

\begin{abstract}
Objectives: To evaluate whether proprotein convertase subtilisin/kexin type 9 inhibitors (PCSK9is) are associated with cardiovascular and safety events in statin-treated patients with cardiovascular risk. Methods: Electronic databases (Pubmed, Cochrane, MEDLINE, EMBASE, ClinicalTrials.gov) were searched through March 31, 2020. Included randomized clinical trials (RCTs) compared PCSK9i use with no PCSK9i in statin treated patients. Two investigators abstracted data and appraised risks of bias. A metaanalysis was performed to calculate risk ratios (RRs) and 95\% CIs using fix-effects models. Adjudicated cardiovascular events (CVE) and adverse drug events (ADE) were defined as the primary outcome. Secondary outcomes were cardiovascular (CV) death, all-cause death, nonfatal myocardial infarction, ischemic stroke, serious ADE and injection-site reaction. Results: A total of 10 RCTs 50,053 participants were included. PCSK9i use was associated with marginal but signigicant reductions in the CVE (RR, 0.87 [95\%CI, 0.830.91]; NNT, 54; $\mathrm{P}<0.00001 ; \mathrm{I}^{2}=0 \%$, heterogeneity $\mathrm{P}=0.86$ ), nonfatal myocardial infarction ( $\mathrm{RR}, 0.86$ [95\% $\mathrm{CI}$, 0.78-0.96]; NNT, 95; $\mathrm{P}=0.005 ; \mathrm{I}^{2}=0 \%$, heterogeneity $\mathrm{P}=0.88$ ), and ischemic stroke ( $\mathrm{RR}, 0.75$ [95\%CI 0.640.87]; NNT, 244; $\mathrm{P}=0.00 ; \mathrm{I}^{2}=0 \%$, heterogeneity $\mathrm{P}=0.82$ ) compared with no PCSK9i in statin-treated patients with CV risk. No significant difference in ADE were found between statins alone and with PCSK9i. The PCSK9i use was associated with signigicant increasing in injection-site reaction (RR, 1.55 [95\%CI 1.38-1.75]; NNT, 101; $\mathrm{P}<0.00001 ; \mathrm{I}^{2}=0 \%$, heterogeneity $\mathrm{P}=0.44$ ). Conclusions: Among statin-treated patients with $\mathrm{CV}$ risk, the use of PCSK9is may marginally improve CVE, nonfatal myocardial infarction and ischemic stroke, but had no significant benefit for cardiovascular death, all-cause mortality, ADE and serious ADE. The use of PCSK9is was well tolerated, but had significantly injection-site reactions.
\end{abstract}

\section{INTRODUCTION}

Proprotein convertase subtilisin/kexin type 9 (PCSK9) has been recently discovered as the third gene involved in autosomal dominant hypercholesterolemia. PCSK9 inhibitors (PCSK9is) are novel cholesterol-lowering agents indicated for patients with familial hypercholesterolemia $(\mathrm{FH})$ and/or very highrisk atherosclerotic cardiovascular disease (ASCVD) who require additional lowering of LDL-C even after maximally tolerated statin therapy (1). PCSK9is are approved in many countries, including the USA, China and across Europe, for the management of patients with hypercholesterolaemia on maximally tolerated statin therapy. Studies have shown that PCSK9is reduce LDL-C levels $50 \%$ to $60 \%$ beyond that 
achieved by statin therapy alone (2-6). Randomized controlled trials (RCT) of both PCSK9is alone and in combination with statins have demonstrated a reduced risk for cardiovascular events (CVE) among patients with ASCVD or following acute coronary syndrome (3). Evidence from the FOURIER trial indicates that evolocumab was equally effective in reducing cardiovascular events in ASCVD patients with baseline LDL-C of $<70$ versus $\geqq 70 \mathrm{mg} / \mathrm{dL}$ and among patients who were on maximal- versus submaximal-potency statins (7).

We aimed at assessing the safety of PCSK9is in reducing $\mathrm{CV}$ endpoint events in patients with hyperlipidemia. Systematic review and metaanalysis were used to report the cardiovascular events and safety of PCSK9i in hyperlipidemia patients with CV risk, based on RCT.

\section{METHODS}

\section{Literature search}

The following databases were searched: PubMed, Cochrane, MEDLINE, EMBASE, CNKI, WANFANG data base and CBM; ClinicalTrials.gov, from database inception until 31th March 2020. The following keywords were used: proprotein convertase subtilisin/kexin type 9 (PCSK9), statin, ezetimibe, alirocumab, evolocumab, AMG145, ALN-PCS02, BMS-962476, LY3015014, RG7652, 1D05-IgG2, PF-05335810, REGN727, SAR236553, randomized controlled trial (RCT). Citations were screened at title/abstract level and retrieved as full reports if considered relevant.

\section{Study selection and data management}

After removal of duplicates, the titles and abstracts of the search results were screened for relevance by both authors. The final list of included studies was decided on by discussion between authors, with full agreement required before inclusion. No disagreements required resolution by a third reviewer. The main inclusion criteria were (i) randomized control trials including at least 100 participants; (ii) enrolled participants with known cardiovascular risk if they had any of the following: clinical atherosclerotic cardiovascular disease
(ASCVD) includes acutecoronary syndrome (ACS), those with history of myocardial infarction, stable or unstable angina or coronary or other arterial revascularization, stroke, transient ischemic attack, or peripheral artery disease including aortic aneurysm, all of atherosclerotic origin; systematic coronary risk evaluation (SCORE) 10-year fatal CVD risk $\geqq 1 \%$; past diagnosis of hypertension; (iii) enrolled participants with basic statin treatment; (iv) had a follow-up of at least 8 weeks; (v) compared PCSK9is at any dose with no PCSK9i (defined as placebo or ezetimibe as a positive control); (vi) reported cardiovascular and safety outcomes of interest; (vii) were published in the English language. All patients were under treatment with statins.

Two reviewers (Z.N.Z and Y.T.Z) independently extracted the following information from each study: study acronym; first author; year; trail NCT number; number of participants; main inclusion criteria; mean follow-up duration; intervention (a PCSK9i at any dose) and control treatment (placebo or ezetimibe); patient demographics; mean cholesterol/LDL/HDL; basic statin therapy. Another author X.H. was consulted if there were any discrepancies. If the RCT had more than two groups or factorial desighs and permitted multiple comparsons, we extracted only the imformation and data of interest reported in the original articles.

\section{Outcomes}

The primary cardiovascular outcome was adjudicated cardiovascular events. Secondary cardiovascular end points included cardiovascular death, all-cause mortality, nonfatal myocardial infarction, and ischemic stroke. The primary safety outcome was adverse drug events. Secondary safety end points included seriouse adverse drug events, and injection-site reactions.

\section{Quality assessments}

Two authors (Z.N.Z and Y.T.Z) independently assessed the selected studies for quality without blinding to journal or study authorship. Included 
RCTs were assessed the risk of bias according to the Cochrane Collaboration's tool from Cochrane Handbook(8). Discrepancies were resolved by involvement of a third author (X.H.) if required.

\section{Statistical analysis}

Trial-level data were analyzed according to the original randomization group for which outcome data were available. We performed meta-analysis to calculate risk ratios (RRs), and 95\%CIs using the Mantel-Haenszel statistical method. Based on the practice recommendation of the Cochrane Handbook, (8) RCTs with zero events in both the intervention and the control groups were not included in the meta-analysis when RRs were calculated.

A fix-effects model was used ro pool the data, and statistical heterogeneity between summary data was evaluated using the $I^{2}$ statistic. Sensitivity analysis was performed by excluding low-quality studies, RCTs recruiting participants with particular conditions, or RCTs with characteristics different from the others.

All meta-analysis were performed using Revman version 5.3 (Cochrane Collaboration). All tests were 2-tailed, and $\mathrm{P}<0.05$ was considered statistically significant.

\section{RESULTS}

\section{Literature search}

The systematic search of articles published before March 31, 2020, identified 3839 articles, of which 10 studies were included. In total, 50568 particiants were enrolled. The whole literature search process was summarized in Figure 1.

\section{Study description}

In 8 RCTs, the patients the control group received placebo plus statin; in 2 RCTs, ezetimibe plus statin. The longest follow-up was 114 weeks, and the mean weighted follow-up was 57.0 weeks. Characteristics of the eligible studies were presented in Table 1.

\section{Quality of included studies}

Seven factors were used to evaluate the bias of included RCTs according to the Cochrane risk of bias tool (Figure 2). Publication bias of primary outcomes ranging from none to moderate was suggested by visual inspection of the funnel plots or by the linear regression approach (Figure 3). The included trials were not significantly different with regard to risk of bias.

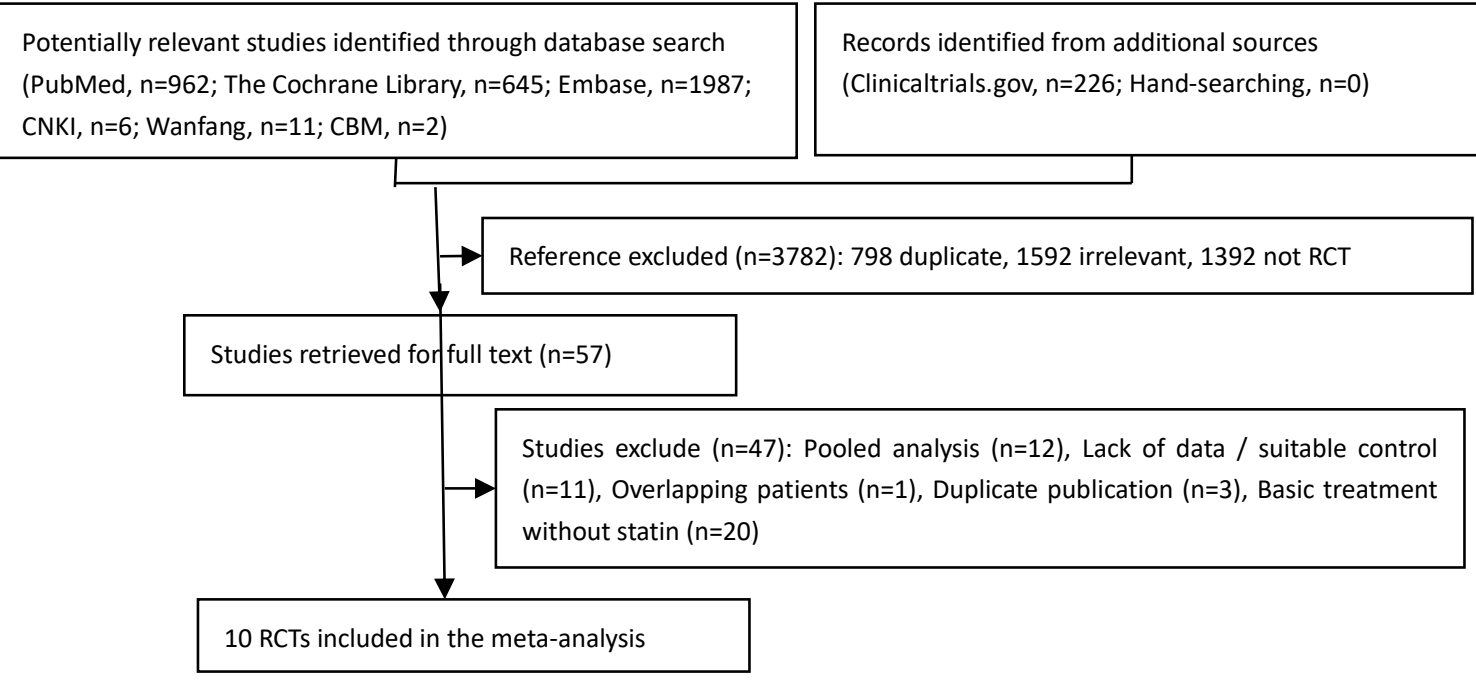

Figure 1. Study Flow Chart 
Table 1. Flowchart of Trial Identification for Meta-analysis

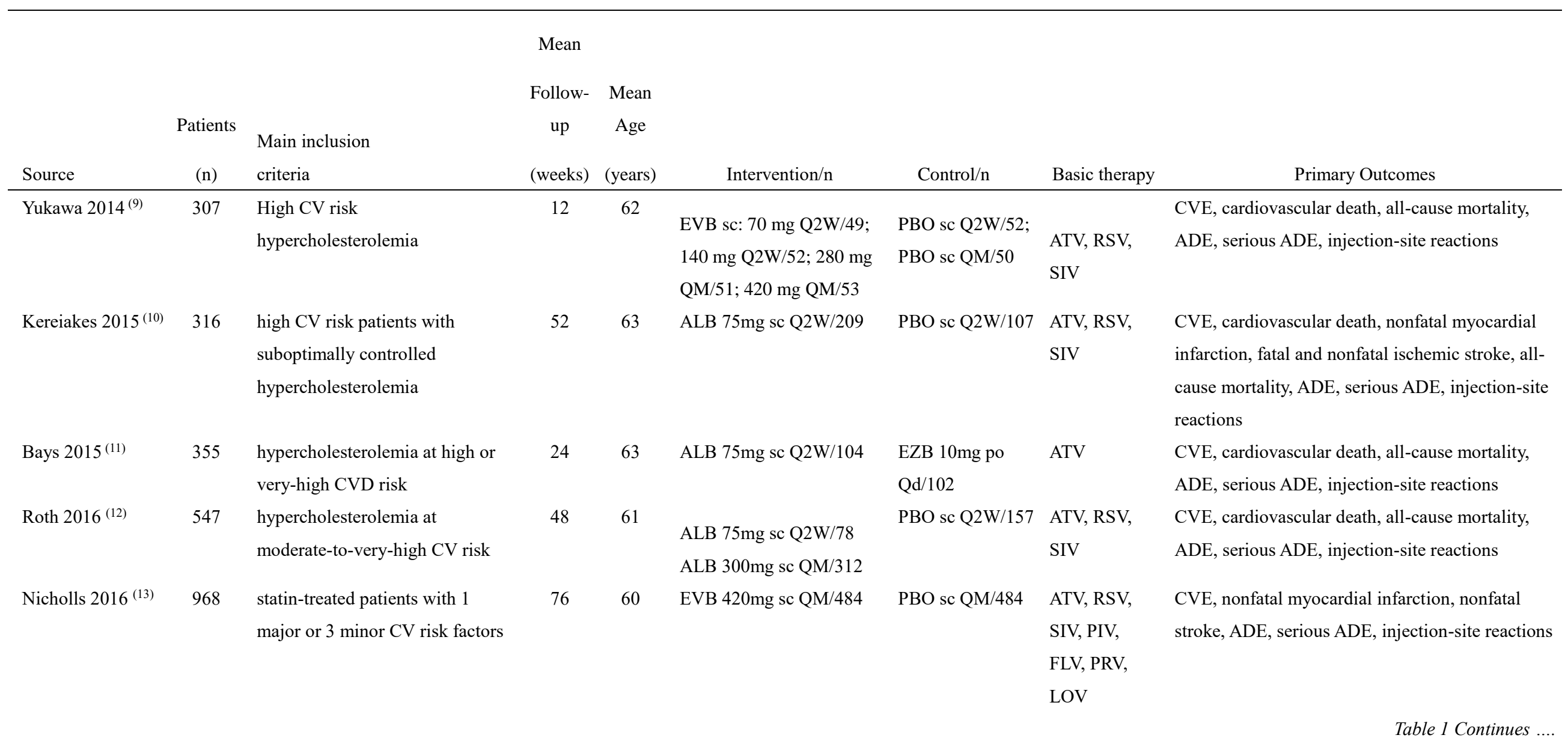




\begin{tabular}{|c|c|c|c|c|c|c|c|c|}
\hline Kiyosue $2016^{(14)}$ & 404 & $\begin{array}{l}\text { hyperlipidemia or mixed } \\
\text { dyslipidemia and high CV risk }\end{array}$ & 12 & 62 & $\begin{array}{l}\text { EVB 140mg sc Q2W/101 } \\
\text { EVB 420mg sc QM/101 }\end{array}$ & $\begin{array}{l}\text { PBO sc Q2W/101 } \\
\text { PBO sc QM/101 }\end{array}$ & ATV & $\begin{array}{l}\text { CVE, nonfatal ischemic stroke, cardiovascular } \\
\text { death, all-cause mortality, ADE, serious ADE, } \\
\text { injection-site reactions }\end{array}$ \\
\hline $\begin{array}{l}\text { Cannon } 2015^{(15) /} \\
\text { Shahawy } 2017^{(16)}\end{array}$ & 720 & $\begin{array}{l}\text { High CV risk patients with } \\
\text { inadequately controlled } \\
\text { hypercholesterolaemia }\end{array}$ & 104 & 61 & ALB 75mg sc Q2W: 479 & $\begin{array}{l}\text { EZB 10mg po Qd } \\
\text { : } 241\end{array}$ & $\begin{array}{l}\text { ATV, RSV, } \\
\text { SIV }\end{array}$ & $\begin{array}{l}\text { CVE, cardiovascular death, nonfatal myocardial } \\
\text { infarction, fatal and nonfatal ischemic stroke, all- } \\
\text { cause mortality, ADE, serious ADE, injection-site } \\
\text { reactions }\end{array}$ \\
\hline Koh $2018^{(17)}$ & 199 & $\begin{array}{l}\text { hypercholesterolemia at high } \mathrm{CV} \\
\text { risk }\end{array}$ & 24 & 61 & ALB 75mg sc Q2W/97 & PBO sc Q2W/102 & $\begin{array}{l}\text { ATV, RSV, } \\
\text { SIV }\end{array}$ & $\begin{array}{l}\text { CVE, nonfatal myocardial infarction, fatal and } \\
\text { nonfatal ischemic stroke, all-cause mortality, } \\
\text { ADE, serious ADE, injection-site reactions }\end{array}$ \\
\hline Sabatine $2017^{(18)}$ & 27564 & $\begin{array}{l}\text { patients with atherosclerotic } \mathrm{CV} \\
\text { disease }\end{array}$ & 114 & 63 & $\begin{array}{l}\text { EVB 140mg sc Q2W or } \\
\text { EVB 420mg sc QM/13784 }\end{array}$ & $\begin{array}{l}\text { PBO sc Q2W or } \\
\text { PBO sc } \\
\text { QM/13780 }\end{array}$ & ATV & $\begin{array}{l}\text { CVE, cardiovascular death, myocardial infarction, } \\
\text { ischemic stroke, hemorrhagic stroke, ischemic } \\
\text { stroke or transient ischemic attack, all-cause } \\
\text { mortality, ADE serious ADE, injection-site } \\
\text { reactions }\end{array}$ \\
\hline Schwartz $2014^{(19)}$ & 18924 & $\begin{array}{l}\text { initiated } 1 \text { to } 12 \text { months after an } \\
\text { index ACS event }\end{array}$ & 104 & 59 & $\begin{array}{l}\text { ALB 75/150mg sc } \\
\text { Q2W/9462 }\end{array}$ & $\begin{array}{l}\mathrm{PBO} s \mathrm{sc} \\
\mathrm{Q} 2 \mathrm{~W} / 9462\end{array}$ & ATV, RSV & $\begin{array}{l}\text { CVE, cardiovascular death, nonfatal myocardial } \\
\text { infarction, fatal and nonfatal ischemic stroke, all- } \\
\text { cause mortality, ADE, serious ADE, injection-site } \\
\text { reactions }\end{array}$ \\
\hline
\end{tabular}

ACS, acute coronary syndrome; ADE, adverse drug event; ALB, alirocumab; ATV, atorvastatin; CV, cardiovascular; CVD, cardiovascular disease; CVE, cardiovascular event; EVB, evolocumab;

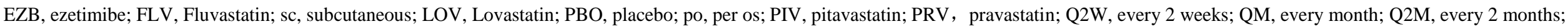
RSV, rosuvastatin; SIV, simvastatin. 


\section{Quality of included studies}

Seven factors were used to evaluate the bias of included RCTs according to the Cochrane risk of bias tool (Figure 2). Publication bias of primary outcomes ranging from none to moderate was suggested by visual inspection of the funnel plots or by the linear regression approach (Figure 3). The included trials were not significantly different with regard to risk of bias.

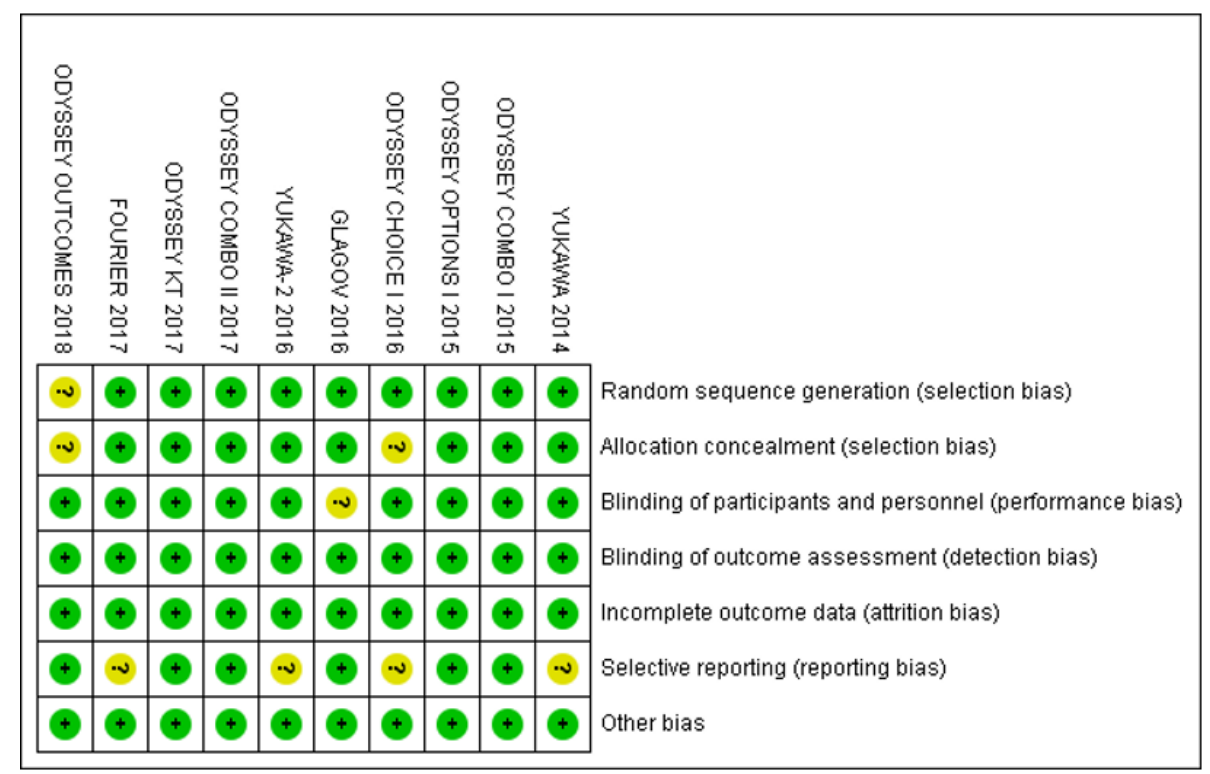

Figure 2. Risk of bias summary review authors' judgements about each risk of bias item for each RCT

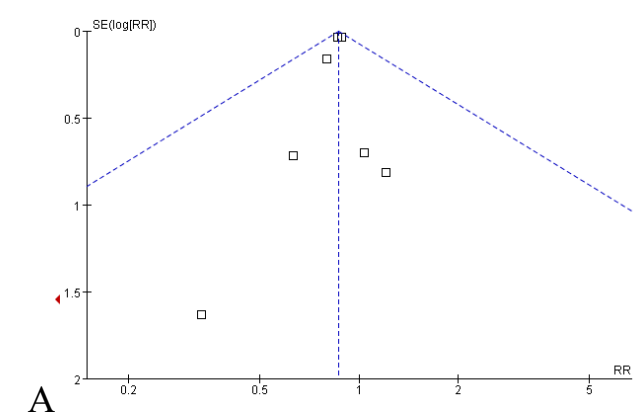

B

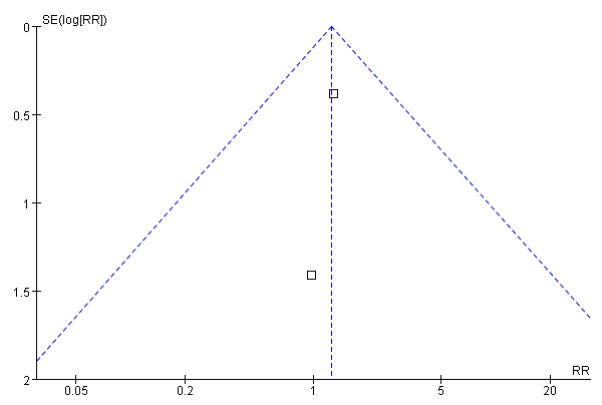

$\mathrm{C}$

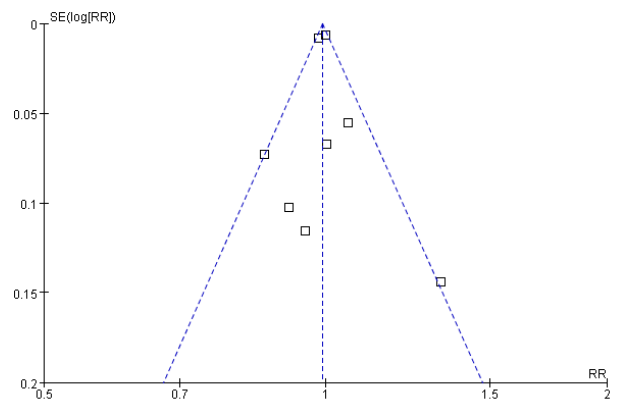

$\mathrm{C}$

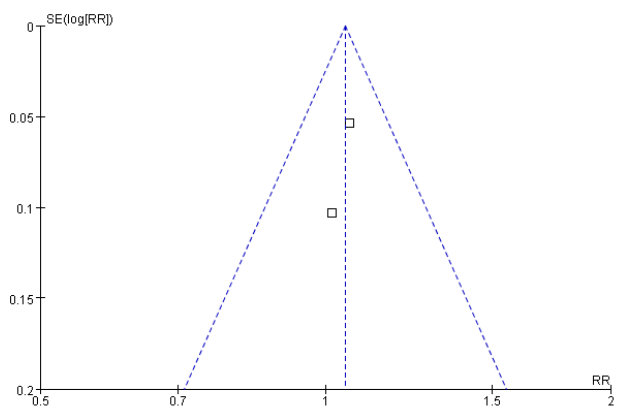

Figure 3. Publication Bias. Cardiovascular Events of PCSK9i vs placebo (A); Cardiovascular Events of PCSK9i vs ezetimibe (B); adverse drug events of PCSK9i vs placebo (C); adverse drug events of PCSK9i vs ezetimibe (D). Markers represent individual studies 


\section{Adjudicated Cardiovascular Events}

Eight RCTs were included in the analysis of CVE comparing PCSK9i with placebo. All patients were taking statins. The treatment with a PCSK9i was associated with a marginal but statistically significant decrease in CVE （RR=0.87, [95\% CI, 0.83-0.91], NNT=54, $\mathrm{P}<0.00001 ; \quad \mathrm{I}^{2}=0 \%$, heterogeneity $\mathrm{P}=0.86 ;$ Figure 4).

Two RCTs were included in the analysis of CVE compared PCSK9i with ezetimibe in statin-treated patients. Compared with ezetimibe, treatment with a PCSK9i was not associated with a statistically significant increase in CVE $(\mathrm{RR}=1.26$, [95\% CI, 0.612.61], NNT $=84, \mathrm{P}=0.53 ; \mathrm{I}^{2}=0 \%$, heterogeneity $\mathrm{P}=0.85$; Figure 5).

\section{Cardiovascular death}

Six RCTs were included in the analysis of cardiovascular death compared PCSK9i with placebo in statin-treated patients. Compared with no treatment with a PCSK9i, treatment with a PCSK9i was not associated with a statistically significant decrease in cardiovascular death $(\mathrm{RR}=0.96$, [95\% CI, 0.85-
1.08], NNT $=823, \mathrm{P}=0.51 ; \mathrm{I}^{2}=0 \%$, heterogeneity $\mathrm{P}=0.38$; Figure 6).

Two RCTs were included in the analysis of cardiovascular death compared PCSK9i with ezetimibe in statin-treated patients. Compared with ezetimibe, treatment with a PCSK9i was not associated with a statistically significant decrease in cardiovascular death $(\mathrm{RR}=0.76,[95 \%$ CI, 0.18-3.24], NNT $=523, \mathrm{P}=0.71 ; \mathrm{I}^{2}=0 \%$, heterogeneity $\mathrm{P}=0.54$; Figure 7).

\section{All-cause mortality}

8 RCTs were included in the analysis of allcause mortality that compared statins alone with statin plus a PCSK9i. PCSK9is did noy significantly reduced all-cause mortality ( $\mathrm{RR}=0.95$, [95\% CI, 0.86-1.05], NNT $=454$, $\mathrm{P}=0.29 ; \mathrm{I} 2=22 \%$, heterogeneity $\mathrm{P}=0.27$; Figure 8).

Two RCTs were included in the analysis of all-cause mortality compared PCSK9i with ezetimibe in statin-treated patients. Compared with ezetimibe, treatment with a PCSK9i was not associated with a statistically significant decrease in all-cause mortality $(\mathrm{RR}=0.47,[95 \%$ CI, 0.16-1.37], NNT $=98, \quad \mathrm{P}=0.17 ; \mathrm{I}^{2}=0 \%$, heterogeneity $\mathrm{P}=0.80$; Figure 9 ).

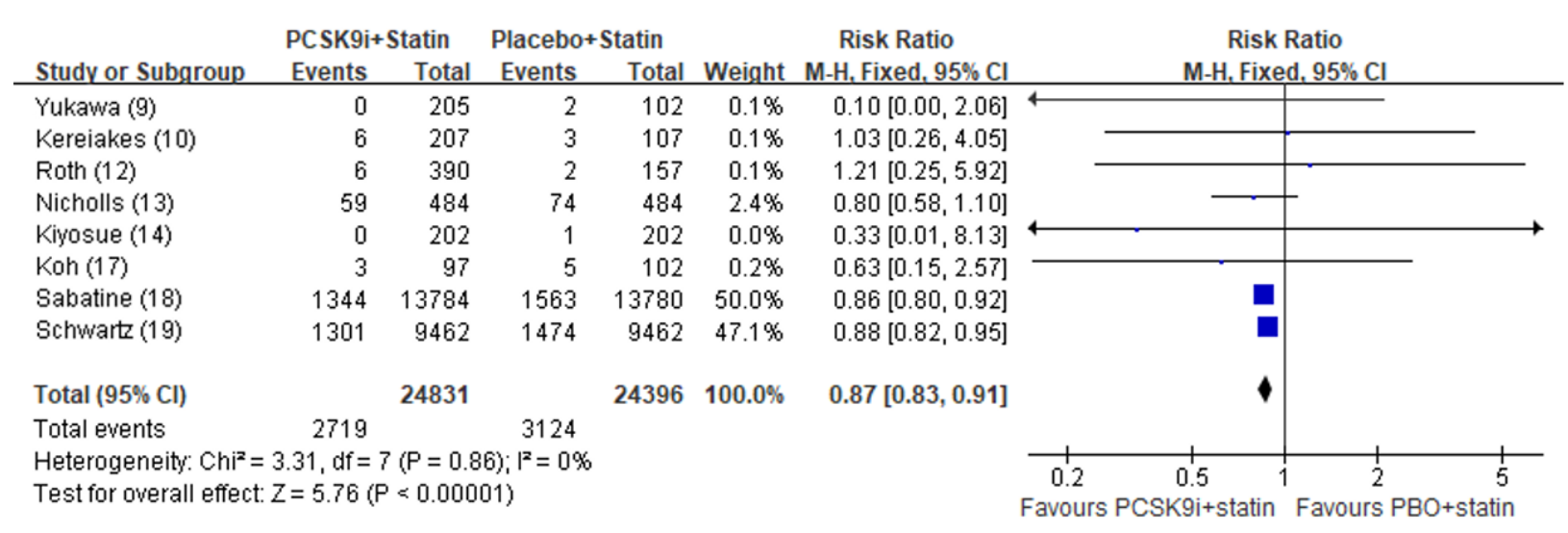

Figure 4. Forest plot depicting the risk ratios of CVE with PCSK9i versus placebo with statin-treated patiens 


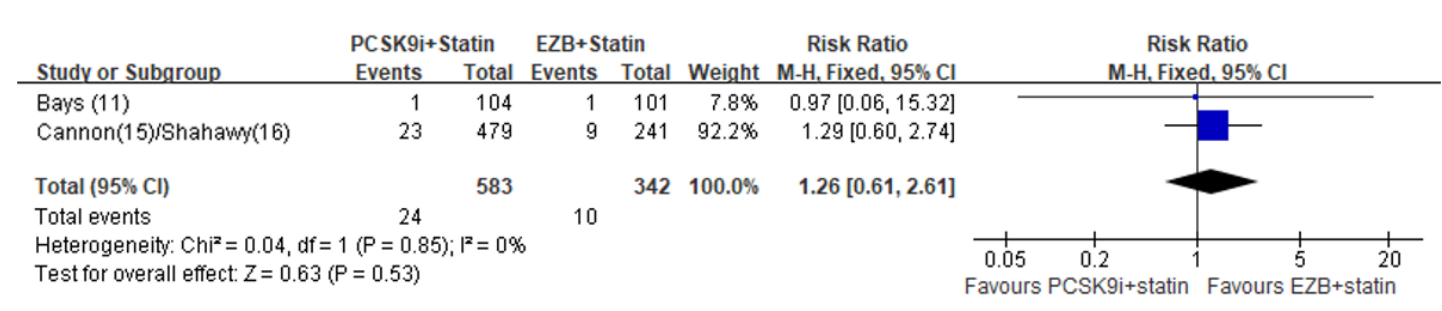

Figure 5. Forest plot depicting the risk ratios of CVE with PCSK9i versus ezetimibe in statin-treated patients

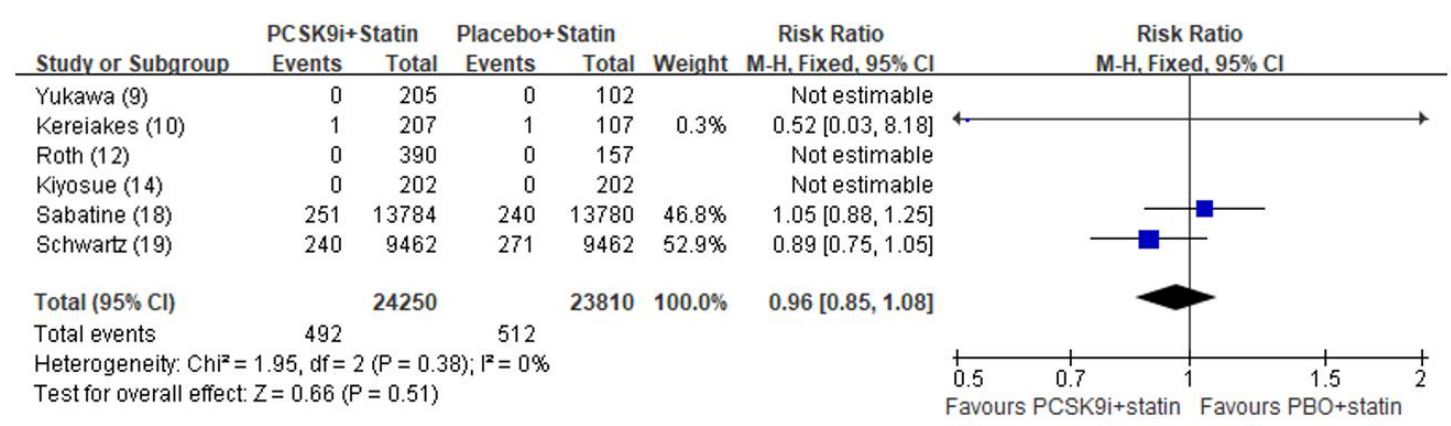

Figure 6. Forest plot depicting the risk ratios of cardiovascular death with PCSK9i versus placebo in statin-treated patients

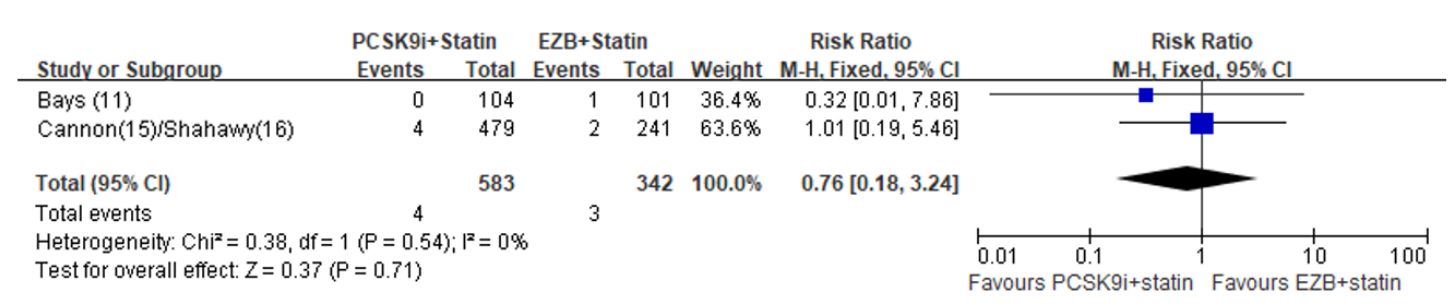

Figure 7. Forest plot depicting the risk ratios of cardiovascular death with PCSK9i versus ezetimibe in statin-treated patients

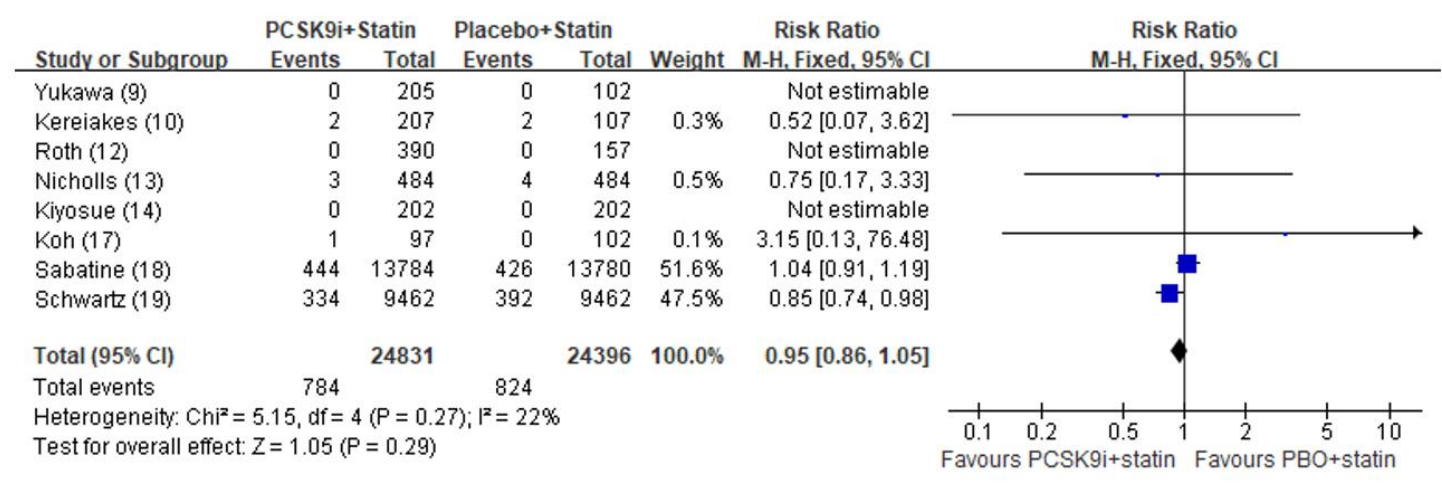

Figure 8. Forest plot depicting the risk ratios of all-cause mortality with PCSK9i versus placebo in statin-treated patients 


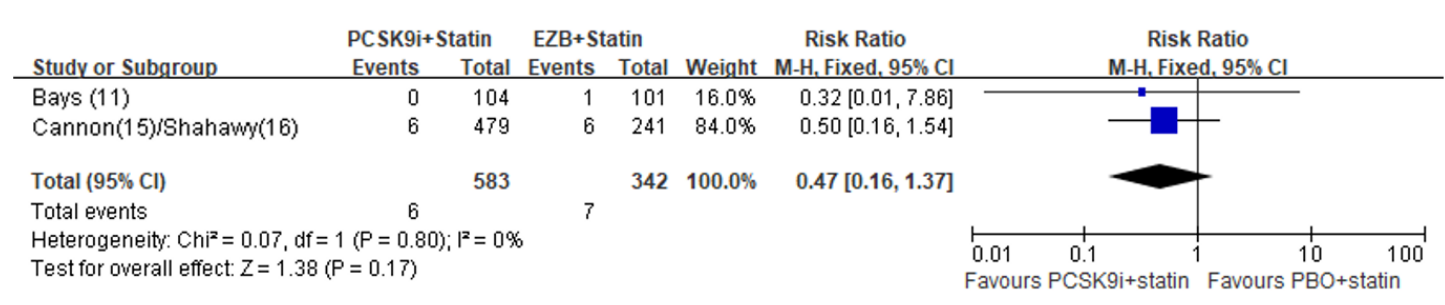

Figure 9. Forest plot depicting the risk ratios of all-cause mortality with PCSK9i versus ezetimibe in statin-treated patients

\section{Nonfatal myocardial infarction}

4 RCTs were included in the analysis of nonfatal myocardial infarction in patients taking statin versus statin plus a PCSK9i.The treatment with a PCSK9i was associated with a smaill but statistically significant decrease in nonfatal myocardial infarction $(\mathrm{RR}=0.86$, [95\% CI, 0.78$0.96]$, NNT $=95, \mathrm{P}=0.005 ; \mathrm{I}^{2}=0 \%$, heterogeneity $\mathrm{P}=0.88$; Figure 10).

\section{Ischemic stroke}

4 RCTs were included in the analysis of ischemic stroke compared PCSK9i with placebo in statintreated patients. PCSK9i treatment was associated with a marginal but statistically significant decrease in ischemic stroke $(\mathrm{RR}=0.75$, [95\% CI, 0.64-0.87], NNT $=244, \mathrm{P}=0.00 ; \mathrm{I}^{2}=0 \%$, heterogeneity $\mathrm{P}=0.82$; Figure 11 ).

\section{Adverse Drug Events}

Eight RCTs were included in the analysis of ADE compared PCSK9i with placebo in statin-treated patients. Compared with the statin only treatment, a PCSK9i treatment was not associated with a statistically significant decrease in $\mathrm{ADE} \quad(\mathrm{RR}=0.99, \quad[95 \% \quad \mathrm{CI}, \quad 0.98-1.00]$, $\mathrm{NNT}=155, \quad \mathrm{P}=0.16 ; \quad \mathrm{I}^{2}=47 \%, \quad$ heterogeneity $\mathrm{P}=0.07$; Figure 12).

Two RCTs were included in the analysis of ADE compared PCSK9i with ezetimibe in statintreated patients. The treatment with a PCSK9i was not associated with a statistically significant increase in $\mathrm{ADE}(\mathrm{RR}=1.05$, [95\% CI, 0.96-1.15], $\mathrm{NNT}=26, \mathrm{P}=0.31 ; \mathrm{I}^{2}=0 \%$, heterogeneity $\mathrm{P}=0.72$; Figure 13).

\begin{tabular}{|c|c|c|c|c|c|c|c|c|c|}
\hline Study or Subgroup & \multicolumn{2}{|c|}{ PCSK9i+Statin } & \multicolumn{2}{|c|}{ Placebo+Statin } & Weight & $\begin{array}{c}\text { Risk Ratio } \\
\text { M- } \mathrm{H} \text {, Fixed, } 95 \% \mathrm{Cl}\end{array}$ & \multicolumn{3}{|c|}{$\begin{array}{c}\text { Risk Ratio } \\
\text { M-H, Fixed, } 95 \% \mathrm{Cl}\end{array}$} \\
\hline Kereiakes (10) & 1 & 207 & 1 & 107 & $0.2 \%$ & $0.52[0.03,8.18]$ & & & \\
\hline Nicholls (13) & 10 & 484 & 14 & 484 & $1.9 \%$ & $0.71[0.32,1.59]$ & & & \\
\hline Koh (17) & 0 & 97 & 1 & 102 & $0.2 \%$ & $0.35[0.01,8.50]$ & & & \\
\hline Schwartz (19) & 626 & 9462 & 722 & 9462 & $97.7 \%$ & $0.87[0.78,0.96]$ & & & \\
\hline Total $(95 \% \mathrm{Cl})$ & & 10250 & & 10155 & $100.0 \%$ & $0.86[0.78,0.96]$ & $\bullet$ & & \\
\hline Total events & 637 & & 738 & & & & & & \\
\hline $\begin{array}{l}\text { Heterogeneity: } \mathrm{Chi}^{2} \\
\text { Test for overall effec }\end{array}$ & $\begin{array}{l}0.66, \mathrm{df}= \\
Z=2.84(\end{array}$ & $\begin{array}{l}(P=0.8 \\
=0.005)\end{array}$ & 8); $\left.\right|^{2}=0 \%$ & & & & $\begin{array}{cc}0.05 & 0.2 \\
\text { Favours } & \text { PCSK9i+statin }\end{array}$ & 1 Favours $\mathrm{P}$ & $\begin{array}{lc}5 & 20 \\
\text { PBO+statin }\end{array}$ \\
\hline
\end{tabular}

Figure 10. Forest plot depicting the risk ratios of nonfatal myocardial infarction with PCSK9i versus placebo in statin-treated patients 


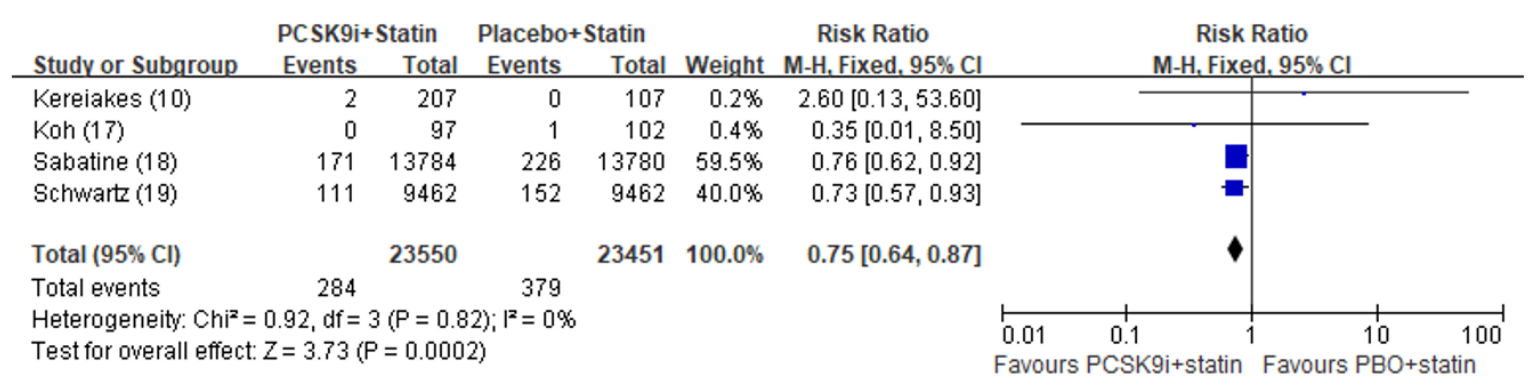

Figure 11. Forest plot depicting the risk ratios of nonfatal myocardial infarction with PCSK9i versus placebo in statin-treated patients

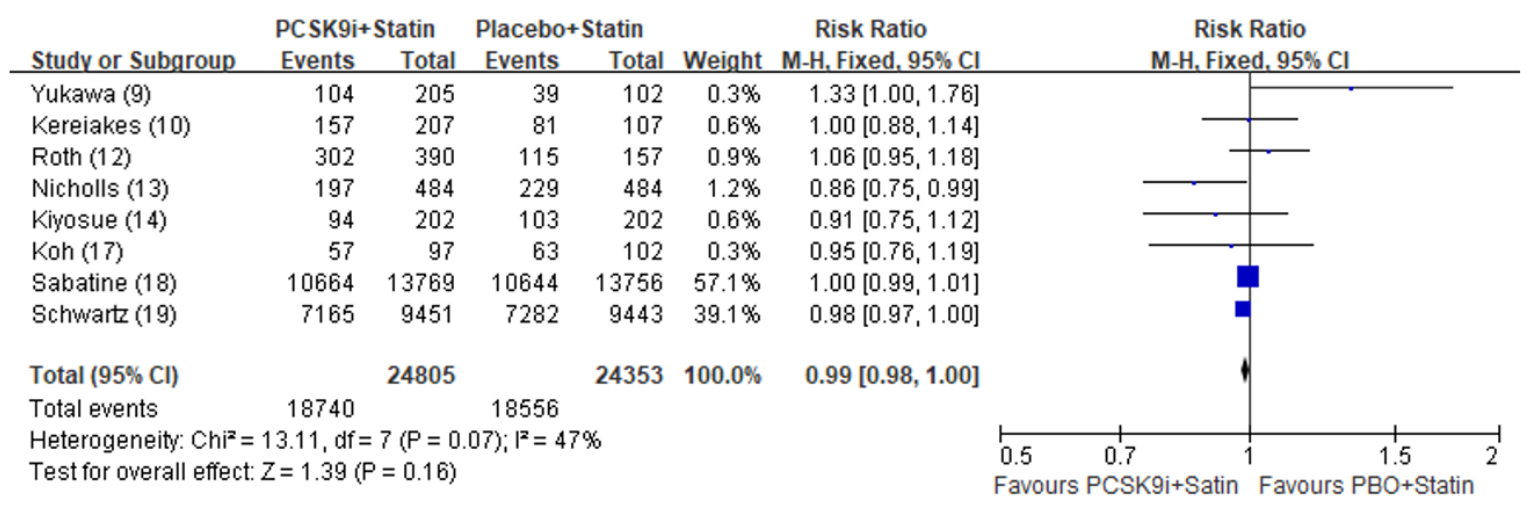

Figure 12. Forest plot depicting the risk ratios of adverse drug events with PCSK9i versus placebo in statin-treated patients

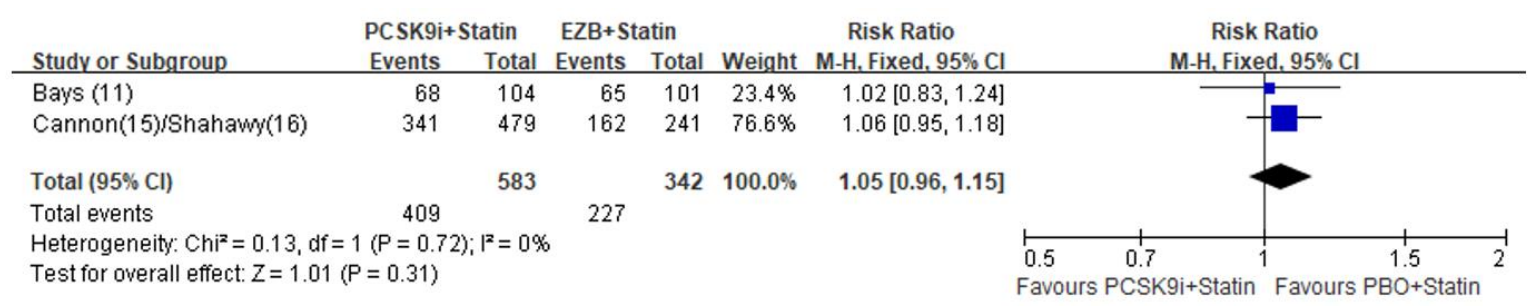

Figure 13. Forest plot depicting the risk ratios of adverse drug events with PCSK9i versus ezetimibe in statin-treated patients

\section{Serious Adverse Drug Events}

Eight RCTs were included in the analysis of serious ADE compared PCSK9i with placebo in statin-treated patients. Compared with no treatment with a PCSK9i, treatment with a PCSK9i was not associated with a statistically significant decrease in serious $\mathrm{ADE}(\mathrm{RR}=0.97$, [95\% CI, 0.94-1.01], NNT=114, $\mathrm{P}=0.10 ; \mathrm{I}^{2}=36 \%$, heterogeneity $\mathrm{P}=0.14$; Figure 14 ).
Two RCTs were included in the analysis of serious ADE compared PCSK9i with ezetimibe in statin-treated patients. Compared with ezetimibe, treatment with a PCSK9i was not associated with a statistically significant decrease in serious $\mathrm{ADE}(\mathrm{RR}=1.00$, [95\% CI, 0.73-1.37], $\mathrm{NNT}=67, \mathrm{P}=0.99 ; \mathrm{I}^{2}=2 \%$, heterogeneity $\mathrm{P}=0.31$; Figure 15). 


\section{Injection-site reaction}

Nine RCTs were included in the analysis of injection-site reaction compared PCSK9i with oral forms in statin-treated patients. Compared with oral forms, treatment with a PCSK9i was associated with a statistically significant increase in serious $\mathrm{ADE}(\mathrm{RR}=1.55$, [95\% CI, 1.38-1.75], $\mathrm{NNT}=101, \quad \mathrm{P}<0.00001 ; \quad \mathrm{I}^{2}=0 \%$, heterogeneity $\mathrm{P}=0.44$; Figure 16).

\begin{tabular}{|c|c|c|c|c|c|c|c|c|}
\hline \multirow[b]{2}{*}{ Study or Subgroup } & \multicolumn{2}{|c|}{ PCSK9i+Statin } & \multicolumn{2}{|c|}{ Placebo+Statin } & \multirow{2}{*}{\multicolumn{2}{|c|}{$\begin{array}{cc} & \text { Risk Ratio } \\
\text { Weight } & \text { M-H. Fixed. } 95 \% \mathrm{Cl} \\
\end{array}$}} & \multirow{2}{*}{\multicolumn{2}{|c|}{$\begin{array}{c}\text { Risk Ratio } \\
\text { M-H, Fixed, } 95 \% \mathrm{Cl}\end{array}$}} \\
\hline & Events & Total & Events & Total & & & & \\
\hline Yukawa (9) & 4 & 205 & 0 & 102 & $0.0 \%$ & $4.50[0.24,82.78]$ & & \\
\hline Kereiakes (10) & 26 & 207 & 14 & 107 & $0.3 \%$ & $0.96[0.52,1.76]$ & & \\
\hline Roth (12) & 43 & 390 & 23 & 157 & $0.5 \%$ & $0.75[0.47,1.21]$ & & \\
\hline Nicholls (13) & 135 & 484 & 142 & 484 & $2.4 \%$ & $0.95[0.78,1.16]$ & & \\
\hline Kiyosue (14) & 1 & 202 & 5 & 202 & $0.1 \%$ & $0.20[0.02,1.70]$ & 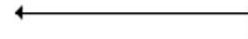 & \\
\hline Koh (17) & 17 & 97 & 10 & 102 & $0.2 \%$ & $1.79[0.86,3.71]$ & & \\
\hline Sabatine (18) & 3410 & 13769 & 3404 & 13756 & $57.1 \%$ & $1.00[0.96,1.04]$ & & \\
\hline Schwartz (19) & 2202 & 9462 & 2350 & 9462 & $39.4 \%$ & $0.94[0.89,0.99]$ & & \\
\hline Total $(95 \% \mathrm{Cl})$ & & 24816 & & 24372 & $100.0 \%$ & $0.97[0.94,1.01]$ & & 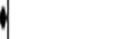 \\
\hline Total events & 5838 & & 5948 & & & & & \\
\hline \multicolumn{7}{|c|}{$\begin{array}{l}\text { Heterogeneity: } \mathrm{Chi}^{2}=10.95, \mathrm{df}=7(P=0.14) ; \mathrm{I}^{2}=36 \% \\
\text { Test for overall effect: } Z=1.64(P=0.10)\end{array}$} & $\begin{array}{cc}1 & 1 \\
0.5 & 0.7 \\
\text { Favours PCSK9i+statin }\end{array}$ & $1 \frac{1.5}{\text { Favours }}$ \\
\hline
\end{tabular}

Figure 14. Forest plot depicting the risk ratios of serious adverse drug events with PCSK9i versus placebo in statin-treated patients

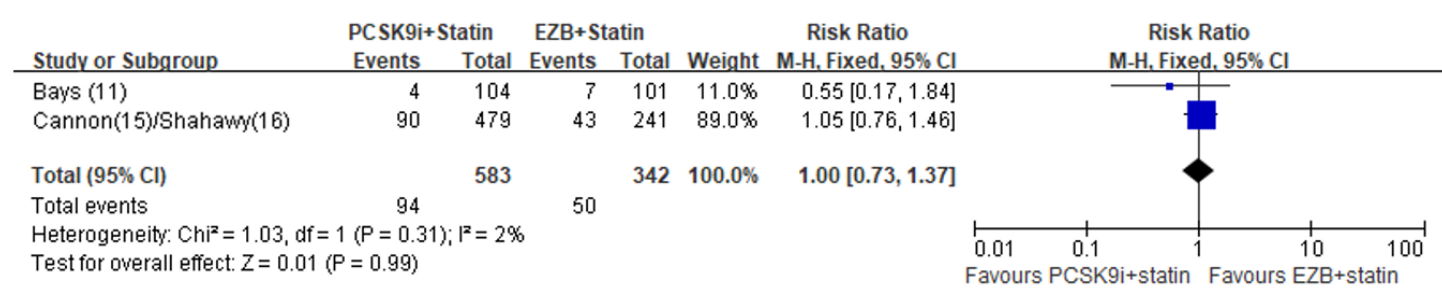

Figure 15. Forest plot depicting the risk ratios of serious adverse drug events with PCSK9i versus ezetimibe in statin-treated patients

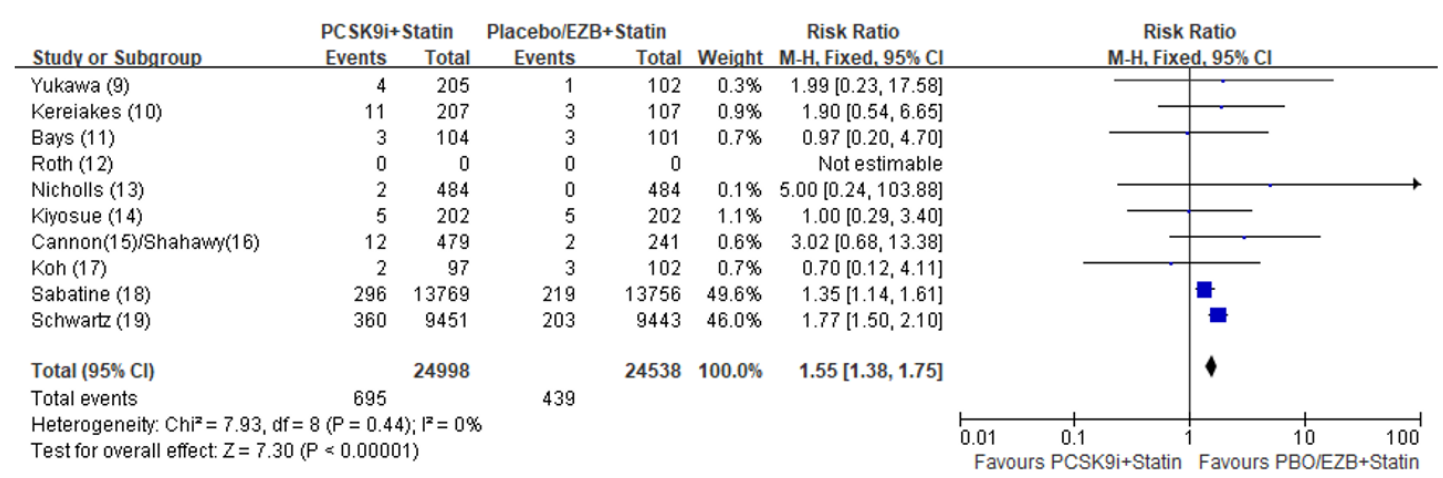

Figure 16. Forest plot depicting the risk ratios of injection-site reaction with PCSK9i versus placebo or ezetimibe in statin-treated patients 


\section{DISCUSSION}

In this meta-analysis of 10 RCTs enrolling 50,053 statin-treated participants with cardiovascular risk, PCSK9i use was associated with marginal reductions in the CVE, nonfatal myocardial infarction, and ischemic stroke. The use of injectable PCSK9is was associatied with an increased risk of injection-site reactions.

PCSK9 is a serine protease crucially involved in determining circulating LDL-C levels by controlling the expression of LDLR on the surface of hepatocytes through a posttranscriptional mechanism (19). Dubuc et al (20) performed a study showed that the NARC-1 gene, PCSK9, was identified as the third locus implicated in autosomal dominant hypercholesterolemia which was strongly induced by statins in a dose-dependent manner.

PCSK9is are fully human monoclonal antibody that binds to and inhibits PCSK9 (21). Two Food and drug administration (FDA)approved monoclonal antibody PCSK9ialirocumab and evolocumab have demonstrated significant LDL-C lowering and improved outcomes in patients with ASCVD when used as adjuncts to maximally tolerated statin therapy (3, 22).

As monotherapy, alirocumab can reduce LDL-C as much as intensive statin treatment (23) and in conjunction with statin, alirocumab greatly enhances LDL-C lowering $(24,25)$. Treatment with alirocumab has been generally well tolerated, with occasional, mild local injection site reactions in homozygous familial hypercholesterolemia (HoFH) and ASCVD patients.

Evolocumab reduces LDL cholesterol levels by approximately $60 \%$ (26-28). Evolocumab has received the approval by the FDA and the European Medicines Agency, as a therapeutic agent for $\mathrm{HoFH}$, primary hypercholesterolemia or dyslipidemia in 2015 (29-31).

The co-published guildlines for the management of dyslipidemia (32) of European
Society of Cardiology (ESC) and European Atherosclerosis Society (EAS) in 2019 comfired that the lipid modification can reduce cardiovascular risk. Guidline showed that for the ACS patients, PCSK9i should be considered as early as possible in patients who have received the maximum tolerated dose of statin and ezetimibe but whose LDL-C levels are not up to standard. In 2017, the National Lipid Association recommended that for the ASCVD patients, especially if there are additional risk factors, PCSK9is may be combined with statins to reduce ASCVD risk after LDL-C $\geqq 70 \mathrm{mg} / \mathrm{dL}$ after treatment with or without the maximum tolerated dose of statin. (33) PCSK9i may be considered to further reduce LDL-C levels in patients with advanced ASCVD who receive a maximum tolerated dose of statins with or without ezebraub and have LDL-C levels of $70 \mathrm{mg} / \mathrm{Dl}$. Practical guidelines for PCSK9is for patients at high cardiovascular risk issued by the ESC/EAS working group in 2017 (34) recommended PCSK9i as primary and secondary preventive therapies for patients with cardiovascular disease.

Karatasakis et al. conducted a meta-analysis (35) on the efficacy and safety of PCSK9i in patients with overall hypercholesterolemia. Results showed that PCSK9i can improve CV outcomes in the treatment of hypercholesterolemia. Casula et al. (36) compared the efficacy of PCSK9i with placebo in the overall population. Results showed that the addition of PCSK9i can significantly reduce the incidence of CVE myocardial infarction and stroke. Different from previous studies, our study limited the inclusion population, as associated $\mathrm{CV}$ risk and statins were used as the primary treatment in all the included studies. This design allows for a more precise comparison of the efficacy and safety of adding PCSK9is to statins in people with CV risk. Similar to the above results, our study showed that the addition of PCSK9i can significantly reduce the incidence of CVE, non-fatal myocardial infarction and 
ischemic stroke. Our study also conducted a meta-analysis on cardiovascular death and allcause death, but the results showed that PCSK9i could not significantly improve event outcome. This results suggest that the addition of a PCSK9i may provide some benefit for people at high risk of myocardial infarction and stroke. The addition of PCSK9is showed no significant advantage in CVE, cardiovascular death or all-cause death comparing with statin combined ezetimibe. It is noted that the study, ODYSSEY OPTIONS I and ODYSSEY COMBO II, involved a small number of people.

For safety outcomes, PCSK9i would not increase the incidence of $\mathrm{ADE}$ and severe $\mathrm{ADE}$ comparing with placebo or ezetimibe. However, as a class of drugs that require subcutaneous injections, PCSK9is can cause injection-site reactions which would affect the acceptability and compliance of this product in clinical application.

\section{Limitations}

Some limitations of our study deserve mention. First, because the PCSK9 inhibitors are relatively new and not widely studied, we were not able to analysis the different doses. Second, some RCTs did not described CVE in details. Third, there were differents in follow-up period between RCTs. Fourth, athough the sample size we included was large, in the results with statistically significant, 95\% CI were close to 1 which indicated a small difference. Whether the results have clinical importance remains to be further studied.

\section{CONCLUSIONS}

First, our study which included a large size of population demonstrated that the addition of PCSK9is on classical statin therapy could marginally but statistically significantly reduce CVE, nonfatal myocardial infarction and ischemic stroke rateamong patients with $\mathrm{CV}$ risk. But there were no significant benefit in cardiovascular death, all-cause mortality, ADE and serious ADE. Second, as there were only two RCTs analyzed the efficacy and safety between PCSK9i and ezetimibe on statin-treated patients at present, it is too early to draw a conclusion about this comparsion. Third, PSCK9is had obvious injection-site reaction which was tolerated. Above all, this study provides some support for the benefit of actively adding PCSK9is on the basis of statins therapy to further reduce some $\mathrm{CVE}$ in patients with $\mathrm{CV}$ risk.

\section{CONFLICT OF INTEREST}

The authors declare no conflict of interest.

\section{ACKNOWLEDGEMENT}

This work was supported by the National key research and development projects (grant number: 2020YFC2003001).

\section{REFERENCES}

1. Grundy SM, Stone NJ, Bailey AL, al. e. 2018 AHA/ACC/AACVPR/AAPA/ABC/ACPM/ADA/ AGS/APhA/ASPC/NLA/PCNA guideline on the management of blood cholesterol: a report of the American College of Cardiology/American Heart Association task force on clinical practice guidelines. J Am Coll Cardiol. 2018;73(24):e285e350. doi: 10.1161/CIR.0000000000000626

2. Navarese E, Kołodziejczak M, Schulze V, Gurbel PA, Tantry U, Lin Y, et al. Effects of proprotein convertase subtilisin/kexin type 9 antibodies in adults with hypercholesterolemia: a systematic review and meta-analysis. Ann Intern Med. 2015;163(1):40-51. doi: 10.7326/M14-2957

3. Sabatine MS, Giugliano RP, Keech AC, Honarpour N, Wiviott SD, Murphy SA, et al. Evolocumab and clinical outcomes in patients with cardiovascular disease. $\mathrm{N}$ Engl J Med. 2017;376(18):1713-22. doi: 10.1056/NEJMoa1615664

4. AlHajri L, AlHadhrami A, AlMheiri S, AlMutawa Y, Z A. The efficacy of evolocumab in the management of hyperlipidemia: a systematic review. Ther Adv Cardiovasc Dis. 2017;11(56):155-69. doi: 10.1177/1753944717698925

5. Catapano AL, Lee LV, Louie MJ, Thompson D, Bergeron J, M K. Efficacy of alirocumab according to background statin type and dose: pooled analysis of 8 ODYSSEY Phase 3 clinical trials. Sci Rep. 2017;7:45788. doi: $10.1038 /$ srep45788 
6. Koren MJ, Sabatine MS, Giugliano RP, Langslet G, Wiviott SD, Kassahun H, et al. Long-term lowdensity lipoprotein cholesterol-lowering efficacy, persistence, and safety of evolocumab in treatment of hypercholesterolemia: results up to 4 years from the open-label OSLER-1 extension study. JAMA Cardiol.2(6):598-607. doi: 10.1001/jamacardio.2017.0747

7. Giugliano RP, Keech A, Murphy SA, Huber K, Tokgozoglu SL, Lewis BS, et al. Clinical efficacy and safety of evolocumab in high-risk patients receiving a statin: secondary analysis of patients with low LDL cholesterol levels and in those already receiving a maximal-potency statin in a randomized clinical trial. JAMA Cardiol. 2017;2(12):1385-91.

doi: 10.1001/jamacardio.2017.3944

8. Higgins JPT. Green S, eds. Cochrane Handbook for Systematic Reviews of Interventions, version 5.1.0 (updated March 2011). .

9. Hirayama A, Honarpour N, Yoshida M, Yamashita S, Huang F, Wasserman SM, et al. Effects of Evolocumab (AMG 145), a Monoclonal Antibody to PCSK9, in Hypercholesterolemic, StatinTreated Japanese Patients at High Cardiovascular Risk. Circulation Journal. 2014;78(5):1073-82. doi: 10.1253/circj.CJ-14-0130

10. Kereiakes DJ, Robinson JG, Cannon CP, Lorenzato C, Pordy R, Chaudhari U, et al. Efficacy and safety of the proprotein convertase subtilisin/kexin type 9 inhibitor alirocumab among high cardiovascular risk patients on maximally tolerated statin therapy: The ODYSSEY COMBO I study. Am Heart J. 2015;169(6):906-15 e13. doi: 10.1016/j.ahj.2015.03.004

11. Bays H, Gaudet D, Weiss R, Ruiz JL, Watts GF, Gouni-Berthold I, et al. Alirocumab as Add-on To Atorvastatin Versus Other Lipid Treatment Strategies: ODYSSEY OPTIONS I Randomized Trial. J Clin Endocrinol Metab. 2015;100(8):31408. doi: $10.1210 /$ jc. $2015-1520$

12. Roth EM, Moriarty PM, Bergeron J, Langslet G, Manvelian G, Zhao J, et al. A phase III randomized trial evaluating alirocumab $300 \mathrm{mg}$ every 4 weeks as monotherapy or add-on to statin: ODYSSEY CHOICE I. Atherosclerosis. 2016;254:254-62. doi: 10.1016/j.atherosclerosis.2016.08.043

13. Nicholls SJ, Puri R, Anderson T, Ballantyne CM, Cho L, Kastelein JJ, et al. Effect of Evolocumab on Progression of Coronary Disease in StatinTreated Patients: The GLAGOV Randomized Clinical Trial. JAMA. 2016;316(22):2373-84. doi: 10.1001/jama.2016.16951

14. Kiyosue A, Honarpour N, Kurtz C, Xue A, Wasserman SM, Hirayama A. A Phase 3 Study of Evolocumab (AMG 145) in Statin-Treated Japanese Patients at High Cardiovascular Risk.
The American Journal of Cardiology. 2016;117(1):40-7. doi: 10.1016/j.amjcard.2015.10.021

15. Cannon CP, Cariou B, Blom D, McKenney JM, Lorenzato C, Pordy R, et al. Efficacy and safety of alirocumab in high cardiovascular risk patients with inadequately controlled hypercholesterolaemia on maximally tolerated doses of statins: the ODYSSEY COMBO II randomized controlled trial. Eur Heart J. 2015;36(19):1186-94.

10.1093/eurheartj/ehv028

16. El Shahawy M, Cannon CP, Blom DJ, McKenney JM, Cariou B, Lecorps G, et al. Efficacy and Safety of Alirocumab Versus Ezetimibe Over 2 Years (from ODYSSEY COMBO II). Am J Cardiol. 2017;120(6):931-9. doi: 10.1016/j.amjcard.2017.06.023

17. Koh KK, Nam CW, Chao TH, Liu ME, Wu CJ, Kim DS, et al. A randomized trial evaluating the efficacy and safety of alirocumab in South Korea and Taiwan (ODYSSEY KT). J Clin Lipidol. 2018;12(1):162-72 e6. doi: 10.1016/j.jacl.2017.09.007

18. Sabatine MS, Giugliano RP, Keech AC, Honarpour N, Wiviott SD, Murphy SA, et al. Evolocumab and Clinical Outcomes in Patients with Cardiovascular Disease. New England Journal of Medicine. 2017;376(18):1713-22. doi: 10.1056/NEJMoa1615664

19. Tibolla G, Norata G, Artali R, al e. Proprotein convertase subtilisin/kexin type 9 (PCSK9): from structure-function relation to therapeutic inhibition, Nutrition, metabolism, and cardiovascular diseases. NMCD. 2011;21:835-43. doi: 10.1016/j.numecd.2011.06.002

20. Dubuc G, Chamberland A, Wassef H, Davignon J, Seidah NG, Bernier L, et al. Statins upregulate PCSK9, the gene encoding the proprotein convertase neural apoptosis-egulated convertase-1 implicated in familial hypercholesterolemia. Arterioscler Thromb Vasc Biol. 2004;24(8):14549. doi: 10.1161/01.ATV.0000134621.14315.43

21. Muller-Wieland D, Leiter LA, Cariou B, Letierce A, Colhoun HM, Del Prato S, et al. Design and rationale of the ODYSSEY DM-DYSLIPIDEMIA trial: lipid-lowering efficacy and safety of alirocumab in individuals with type 2 diabetes and mixed dyslipidaemia at high cardiovascular risk. Cardiovasc Diabetol. 2017;16(1):70. doi: 10.1186/s12933-017-0552-4

22. Schwartz GG, Steg PG, Szarek M, Bhatt DL, Bittner VA, Diaz R, et al. Alirocumab and Cardiovascular Outcomes after Acute Coronary Syndrome. N Engl J Med. 2018;379(22):2097-107. doi: 10.1056/NEJMoa1801174

23. Stein EA, Mellis S, Yancopoulos GD, al. e. Effect 
of a monoclonal antibody to PCSK9 on LDL cholesterol. N Engl J Med. 2012;366(12):1108-18. doi: 10.1056/NEJMoa1105803

24. McKenney JM, Koren MJ, Kereiakes DJ, Hanotin C, Ferrand AC, Stein EA. Safety and efficacy of a monoclonal antibody to proprotein convertase subtilisin/kexin type 9 serine protease, SAR236553/REGN727, in patients with primary hypercholesterolemia receiving ongoing stable atorvastatin therapy. J Am Coll Cardiol. 2012;59(25):2344-53.

doi: 10.1016/j.jacc.2012.03.007

25. Stein EA, Gipe D, Bergeron J, Gaudet D, Weiss R, Dufour R, et al. Effect of a monoclonal antibody to PCSK9, REGN727/SAR236553, to reduce lowdensity lipoprotein cholesterol in patients with heterozygous familial hypercholesterolaemia on stable statin dose with or without ezetimibe therapy: a phase 2 randomised controlled trial. The Lancet. 2012;380(9836):29-36. doi: 10.1016/s0140-6736(12)60771-5

26. Blom DJ, Hala T, Bolognese M, al e. A 52-week placebo-controlled trial of evolocumab in hyperlipidemia. N Engl J Med. 2014;370(19):1809-19. doi: 10.1056/NEJMoa1316222

27. Robinson JG, Nedergaard BS, Rogers WJ, Fialkow J, Neutel JM, Ramstad D, et al. Effect of evolocumab or ezetimibe added to moderate- or high-intensity statin therapy on LDL-C lowering in patients with hypercholesterolemia: the LAPLACE-2 randomized clinical trial. JAMA. 2014;311(18):1870-82.

doi: 10.1001/jama.2014.4030

28. Koren MJ, Lundqvist P, Bolognese M, Neutel JM, Monsalvo ML, Yang J, et al. Anti-PCSK9 monotherapy for hypercholesterolemia: the MENDEL-2 randomized, controlled phase III clinical trial of evolocumab. J Am Coll Cardiol. 2014;63(23):2531-40.

doi: 10.1016/j.jacc.2014.03.018

29. European Medicines Agency. Repatha (evolocumab): EU summary of product characteristics. 2015. http://www.ema.europa.eu/ . Accessed 9 Nov 2015.

30. Amgen Inc. Repatha_(evolocumab) injection, for subcutaneous use: US prescribing information. $2015 . \quad$ http://pi.amgen.com/ united_states/repatha/repatha_pi_hcp_english.pdf. Accessed 9 Nov 2015.

31. Health Canada. Repatha (evolocumab) solution for subcutaneous injection: Canadian product monograph. 2015. http://www.hc-sc. gc.ca/. Accessed 9 Nov 2015.

32. Mach F, Baigent C, Catapano AL, Koskinas KC, Casula M, Badimon L, et al. 2019 ESC/EAS Guidelines for the management of dyslipidaemias: lipid modification to reduce cardiovascular risk. European Heart Journal. 2019;290:140-205. doi: 10.1093/eurheartj/ehz455

33. Orringer CE, Jacobson TA, Saseen JJ, Brown AS, Gotto AM, Ross JL, et al. Update on the use of PCSK9 inhibitors in adults: Recommendations from an Expert Panel of the National Lipid Association. J Clin Lipidol. 2017;11(4):880-90. doi: 10.1016/j.jacl.2017.05.001

34. Landmesser U, Chapman MJ, Farnier M, Gencer B, Gielen S, Hovingh GK, et al. European Society of Cardiology/European Atherosclerosis Society Task Force consensus statement on proprotein convertase subtilisin/kexin type 9 inhibitors: practical guidance for use in patients at very high cardiovascular risk. Eur Heart J. 2017;38(29):2245-55. doi: 10.1093/eurheartj/ehw480

35. Karatasakis A, Danek BA, Karacsonyi J, Rangan BV, Roesle MK, Knickelbine T, et al. Effect of PCSK9 Inhibitors on Clinical Outcomes in Patients With Hypercholesterolemia: A Meta-Analysis of 35 Randomized Controlled Trials. Journal of the American Heart Association. 2017;6(12). doi: 10.1161/jaha.117.006910

36. Casula M, Olmastroni E, Boccalari MT, Tragni E, Pirillo A, Catapano AL. Cardiovascular events with PCSK9 inhibitors: an updated meta-analysis of randomised controlled trials. Pharmacol Res. 2019;143:143-50. doi: 10.1016/j.phrs.2019.03.021 